\title{
Expression of Cysteine Proteinases Cathepsins B and K and of Cysteine Proteinase Inhibitor Cystatin C in Giant Cell Tumor of Tendon Sheath
}

Torsten Hansen, M.D., Peter K. Petrow, M.D., Andreas Gaumann, M.D., Gernot M. Keyszer, M.D., Ph.D., Mike Otto, M.D., C. James Kirkpatrick, M.D., Ph.D., D.Sc., Jörg Kriegsmann, M.D., Ph.D.

Institute of Pathology, Johannes Gutenberg-University, Mainz, Germany (TH, AG, MO, CJK, JK); Institute of Pathology, Friedrich-Schiller University, Jena, Germany (PKP); and Department of Internal Medicine I, University of Halle-Wittenberg, Halle, Germany (GMK)

The expression of cysteine proteinases cathepsins B and $K$ and of the endogenous inhibitor of cysteine proteinases, cystatin $\mathrm{C}$, was investigated in tissue specimens of patients with giant cell tumor of tendon sheath (GCTTS). Expression of both enzymes was examined by immunohistochemistry in tissue specimens of 14 patients with GCTTS. Applying double-labeling techniques, the coexpression of cathepsin $B$ and its major endogenous inhibitor cystatin C was additionally studied. Cells expressing the respective proteins were further characterized with the macrophage markers HAM56 and antiCD68 (clone PG-M1). Cathepsin B could be detected in numerous HAM56-positive mononuclear cells (MC), but only in very few giant cells (GC). In contrast, cathepsin $\mathrm{K}$ was predominantly identified in GC that were also strongly immunoreactive for cystatin $C$ and CD68. Coexpression of cathepsin B and cystatin C occurred only in a few MC. The strong expression of both cathepsin $B$ and $K$ suggests that in GCTTS, bone erosion might be mediated not only by pressure of the proliferative tissue, but also by matrix-degrading cysteine proteinases. Because previous studies showed that osteoclasts express high levels of $\mathrm{CD68}$, cathepsin $\mathrm{K}$, and cystatin $\mathrm{C}$ but not of cathepsin $B$, our study contributes to the view that GC of GCTTS and osteoclasts are closely associated.

Copyright (C) 2001 by The United States and Canadian Academy of Pathology, Inc.

VOL. 14, NO. 4, P. 318, 2001 Printed in the U.S.A.

Date of acceptance: September 8, 2000.

Address reprint requests to: Jörg Kriegsmann, M.D., Ph.D., Institute of Pathology, University of Mainz, Langenbeckstrasse 1, D-55101, Mainz, Germany; e-mail: kriegsmann@pathologie.klinik.uni-mainz.de; fax: 49-6131-176604.
KEY WORDS: Bone erosion, Cathepsin B, Cathepsin $\mathrm{K}$, Cystatin C, Giant cell tumor of tendon sheath, Osteoclast-like giant cells.

Mod Pathol 2001;14(4):318-324

Giant cell tumor of tendon sheath (GCTTS) is a proliferative synovial lesion of unknown etiology (1, 2). Theories concerning the dignity and pathogenesis of this disorder have undergone constant revision. GCTTS was believed by some to represent a reactive or hyperplastic process (3). Recent studies demonstrated a variety of chromosomal abnormalities suggesting that GCTTS is most likely neoplastic in nature $(1,4,5)$. GCTTS is divided into localized and diffuse forms (1). The diffuse type is generally regarded as the soft-tissue counterpart of diffuse pigmented villonodular synovitis of the joint space. The localized form, also called nodular tenosynovitis, predominantly affects the digits $(1,2)$. In this localization, it is the second most common tumor after ganglion (6). Less frequently, localized GCTTS occurs in areas of large weight-bearing joints such as the hip, knee, ankle, and foot (1). It typically affects adults between the fourth and sixth decade (1-3).

Histologically, GCTTS is composed of mononuclear polygonal cells and multinucleated giant cells set in a variably dense collagenous stroma $(1,7)$. Numerous immunohistochemical studies indicate that the majority of mononuclear cells (MC) express several markers of the monocyte/macrophage lineage, whereas the multinucleated giant cells (GC) share phenotypic features of osteoclasts $(1,2,8,9)$. Furthermore, GC are thought to form by fusion of monocyte/macrophage-like MC $(7,10)$.

Although GCTTS usually causes no particular symptoms other than a painless palpable nodule, it is able to cause osseous erosion $(1,6,8)$. These erosions are suggested to occur because of pressure 
from the proliferative tissue (6). However, destruction of adjacent bone by an invasive tissue front has been observed as well $(8,11)$. Furthermore, Athanasou et al. (12) found that GC isolated from GCTTS demonstrated resorption pit formation when cultured on cortical bone slides. They concluded that these GC are capable of bone resorption. A variety of matrix-degrading enzymes has been suggested to contribute to bone and cartilage damage in other synovial lesions, such as rheumatoid arthritis and pigmented villonodular synovitis. Besides matrix metalloproteinases (MMP), the cysteine proteinases cathepsin B and the recently found Type $\mathrm{K}$ are especially involved in the destruction of the extracellular matrix (13-17). Cathepsin B is able to degrade different types of collagen and proteoglycans as well as the bone matrix protein osteocalcin (16, 17). It may play a significant role in the degradative process; it also has been demonstrated to activate the metalloproteinases interstitial collagenase (MMP-1) and stromelysin (MMP-3; 18, 19). Cathepsin $\mathrm{K}$ is considered to play a central role in bone resorption because it degrades large amounts of the major bone collagen Type I and the bone matrix protein osteonectin $(20,21)$. Deficiency of cathepsin K results in pyknodysostosis, an autosomal recessive osteosclerotic skeletal dysplasia (22). Specific exogenous inhibitors of both cathepsin B and cathepsin $\mathrm{K}$ have been shown to significantly decrease the destruction of articular cartilage and bone (23-25).

This study was designed to investigate the expression of the cysteine proteinases cathepsins B and $\mathrm{K}$ in GCTTS. Because matrix destruction may be a result of a shifted equilibrium between the proteinase and its inhibitor $(14,15)$, we examined the expression of both cathepsin B and its most potent endogenous inhibitor, cystatin C (26). Immunohistochemical techniques, including doublelabeling methods, were performed to analyze the colocalization of cathepsin B and cystatin C. Furthermore, cells expressing the respective molecules were determined by double staining with the macrophage markers HAM56 (in the case of cathepsin B) or anti-CD68 (in the case of cystatin C).

\section{MATERIALS AND METHODS}

\section{Patient Selection and Tissue Preparation}

Tissue samples of 14 patients with GCTTS were obtained from local excision. Of the 14 patients, 6 were female and 8 were male. The ages of the patients at the initial surgical procedure ranged from 26 to 70 years (mean, 52.2 y). The tumors ranged in size from $0.6 \mathrm{~cm}$ to $2.8 \mathrm{~cm}$ at the greatest diameter, with an average size of $1.5 \mathrm{~cm}$.
Specimens were fixed in $4 \%$ phosphate buffered saline-buffered formaldehyde according to standard methods. Four-micrometer paraffin sections were mounted on silane-coated slides, dewaxed, and hydrated through gradient alcohols. Sections were then incubated at $37^{\circ} \mathrm{C}$, either in $0.1 \%$ trypsin (Sigma, St. Louis, MO) for 15 minutes or in $0.1 \%$ proteinase $\mathrm{K}$ (Boehringer Mannheim, Mannheim, Germany) for 10 minutes.

\section{Immunohistochemistry}

Single staining with monoclonal antibodies against human cathepsin K (clone 182-12G5; Chemicon, Temecula, CA) was performed using the streptavidine-alkaline phosphatase technique. As control, mouse immunoglobulins (Cymbus Biotechnology, Chandlers Ford, United Kingdom) were used to replace the primary antibodies. Tissue specimens from a patient with a giant cell tumor of bone were applied as positive control (27). Slides were treated with an avidin/biotin blocking kit (Vector, Burlingame, CA). After that, nonspecific binding of immunoglobulins was blocked by incubation with $4 \%$ nonfat, dried bovine milk (Sigma) $/ 2 \%$ normal horse serum (Vector) in Tris buffer ( $\mathrm{pH}$ 7.6). Primary antibodies diluted 1:2000 and negative control (diluted 1:200) in Tris buffer $(\mathrm{pH}$ 7.6) were then incubated for 1 hour, followed by a 30-minute incubation with biotinylated horse antimouse IgG (Vector). Slides were then covered with streptavidine-conjugated alkaline phosphatase (1:50 dilution; Dako, Glostrup, Denmark) for 30 minutes. The color reaction was performed using the new fuchsin method (28). Endogenous alkaline phosphatase was blocked by adding levamisole (Sigma) to the substrate solution. Color development was stopped under microscopic control by immersing the slides in Tris buffer ( $\mathrm{pH}$ 7.6). Finally, slides were counterstained with Mayer's hematoxylin (Merck, Darmstadt, Germany) and mounted in Kaiser's glycerol gelatin (Merck).

In the case of single staining with polyclonal rabbit anti-human cystatin C primary antibodies (Dako and Upstate Biotechnology, Lake Placid, NY), the immunogold-silver technique was performed according to previous protocols (29). The immunoglobulin fraction of nonimmunized rabbits (Dako) was used as control. After silver enhancement, a counterstaining technique with Harris' hematoxylin (Merck) and light green (Chroma, Köngen, Germany) was applied. Slides were then mounted in entellan (Merck).

For immunohistochemical double labeling, the APAAP method was applied using mouse monoclonal antibodies against human CD68 (clone PG-M1; Dako) and cathepsin B (clone CA10; Oncogene Research Products, Cambridge, CA). As control, pri- 
mary antibodies were omitted, or mouse immunoglobulins (Dako; Cymbus Biotechnology) were applied to replace the primary antibodies. The APAAP method was performed according to previous protocols (29). Subsequently, the immunogold silver staining technique was applied with antihuman cystatin C. After silver enhancement, slides were counterstained with Mayer's hematoxylin and mounted with Kaiser's glycerol gelatin.

In the case of double labeling with anti-cathepsin B (clone CA10, Oncogene Research Products, Cambridge, CA) and the macrophage marker HAM56 (clone HAM56; Dako), the avidin biotin-complex method with monoclonal HAM56-antibody was applied first. Slides were rinsed with $10 \%$ methanol $/ 4 \% \mathrm{H}_{2} \mathrm{O}_{2}$ for 30 minutes to quench endogenous peroxidase. Nonspecific binding was blocked by $2 \%$ normal goat serum (Vector). The HAM56-antibody (diluted 1:50) was applied, followed by incubation with biotinylated goat anti-mouse IgM (Vector, diluted 1:50). Slides were then covered with the avidin biotin complex kit (Vectastain, Vector) for $30 \mathrm{~min}$ utes. Color development was performed wíth 3,3'diaminobenzidine (Sigma). After that, the APAAP method with anti-cathepsin B was used. Finally, slides were counterstained with Mayer's hematoxylin and mounted with Kaiser's glycerol gelatin.

\section{Light Microscopy}

Slides were examined and photographed with a Leica Microscope DMRX (Leitz, Wetzlar, Germany). Microscopic evaluation of the slides was made according to a modified method of Keyszer et al. (14). The immunohistochemical analysis of all slides was performed on the same day. Cell types were monitored as multinucleated giant cells (GC) and mononuclear cells (MC). The extent of binding was estimated by counting the number of positive cells per 5 high-power fields. Results were classified according to four categories: $(+),<5 \%$ of cells positive; + , between $5 \%$ and $30 \%$ of cells positive; ++ , between $30 \%$ and $60 \%$ of cells positive;,$+++>60 \%$ of cells positive. Final scores represent the average of scores for all tissue specimens examined.

\section{RESULTS}

The results of the microscopic evaluation of the tissue specimens are summarized in Table 1. Ca-

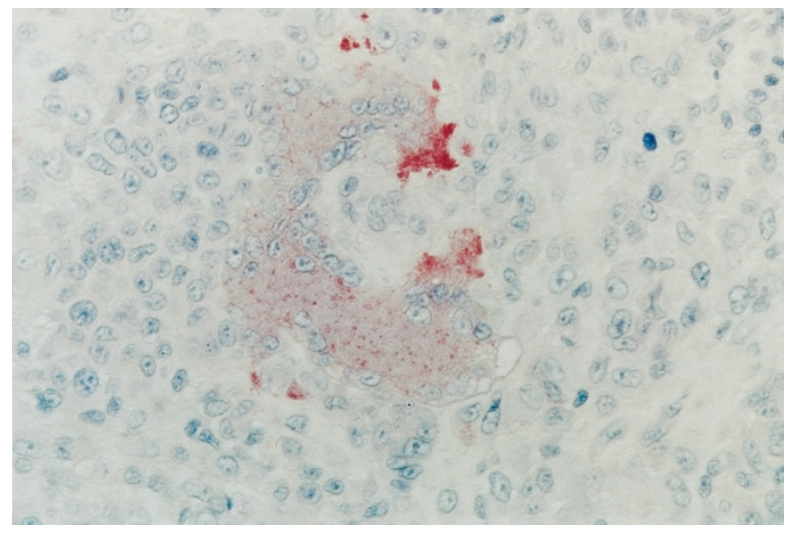

FIGURE 1. Single staining of cathepsin K (red) reveals strong immunoreactivity in a giant cell, whereas only a few mononuclear cells are positive for this molecule. Counterstaining with hematoxylin $(400 \times)$.

thepsin $\mathrm{K}$ was expressed in a large number of giant cells (GC), whereas only a few mononuclear cells (MC) displayed immunoreactivity for this molecule (Fig. 1). Cathepsin K was typically localized in cytoplasmic vacuole-like structures. Positive controls revealed strong cathepsin $\mathrm{K}$ expression in the majority of the GC. In contrast to cathepsin K, cathepsin B could be demonstrated in numerous MC, but only in very few GC in distinct cellular compartments. Positive MC coexpressed the macrophage marker HAM56 as well, whereas HAM56 was negative in GC (Fig. 2).

Strong cystatin $\mathrm{C}$ labeling was found in a large percentage of GC. In these cells, the cystatin C staining pattern was marked in the perinuclear area (Figs. 3, 4). Coexpression of CD68 could be detected in abundant GC. Besides numerous GC, cystatin C was found in a few CD68-positive and -negative $\mathrm{MC}$ as well (Fig. 5). Coexpression of cystatin $\mathrm{C}$ and cathepsin B occurred in the minority of the MC and in very few GC (Fig. 6).

Close apposition of cystatin C positive GC with distinct MC was commonly observed (Figs. 2, 4, 6). The MC coexpressing cathepsin B and HAM56 were frequently arranged around the GC. Interestingly, double labeling of cathepsin B and cystatin C demonstrated that the cystatin C-positive GC were surrounded by cathepsin B-positive MC as well (Figs. $2,6)$.

Negative controls did not reveal staining.

TABLE 1. Results of Immunohistochemical Stains

\begin{tabular}{ccccccc}
\hline $\begin{array}{c}\text { Cell } \\
\text { Type }\end{array}$ & CC & CB & CK & CC + CB & CC + CD68 & CB + HAM56 \\
\hline GC & +++ & $(+)$ & +++ & $(+)$ & +++ & $(+)$ \\
MC & + & ++ & $(+)$ & + & $(+)$ & ++ \\
\hline
\end{tabular}

Expression was scored as follows: $(+)=0-5 \%$ positive cells; $+=5-30 \%$ positive cells; $++=30-60 \%$ positive cells; $+++=60-100 \%$ positive cells. $\mathrm{CB}$, cathepsin $\mathrm{B}$; CC, cystatin C; CK, cathepsin K; GC, giant cells; MC, mononuclear cells. 


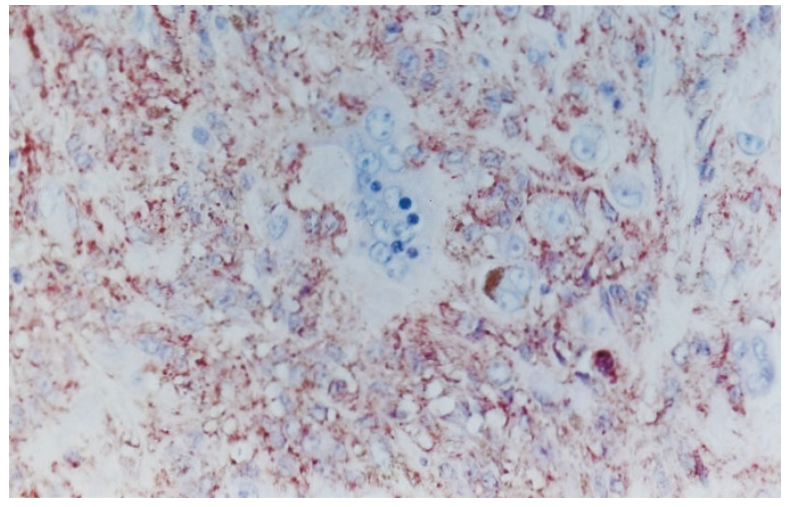

FIGURE 2. Prominent coexpression of HAM56 (brown) and cathepsin $\mathrm{B}$ (red) in numerous mononuclear cells (MC) but not in giant cells (GC). Note that several cathepsin B-positive MC are arranged around the GC. Counterstaining with hematoxylin $(500 \times)$.

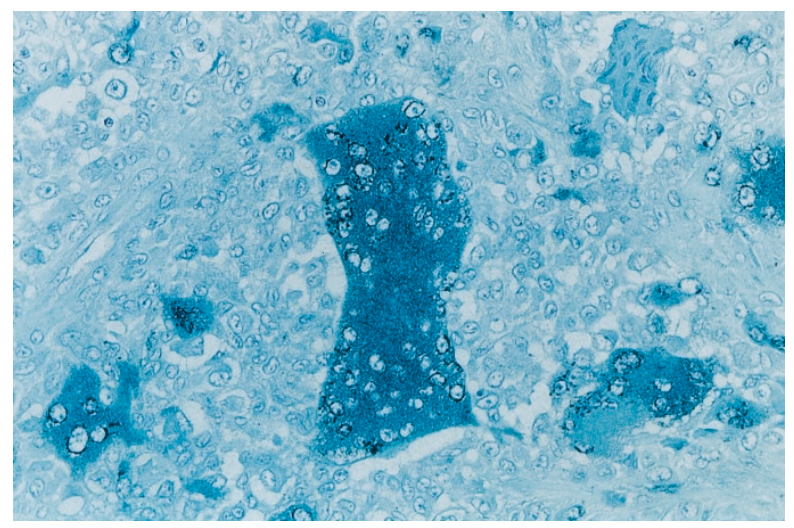

FIGURE 3. Strong cystatin C expression (black) in numerous giant cells, but only in a few mononuclear cells. Besides granular cytoplasmic staining, there is a perinuclear marked expression. Counterstaining with light green and hematoxylin $(400 \times)$.

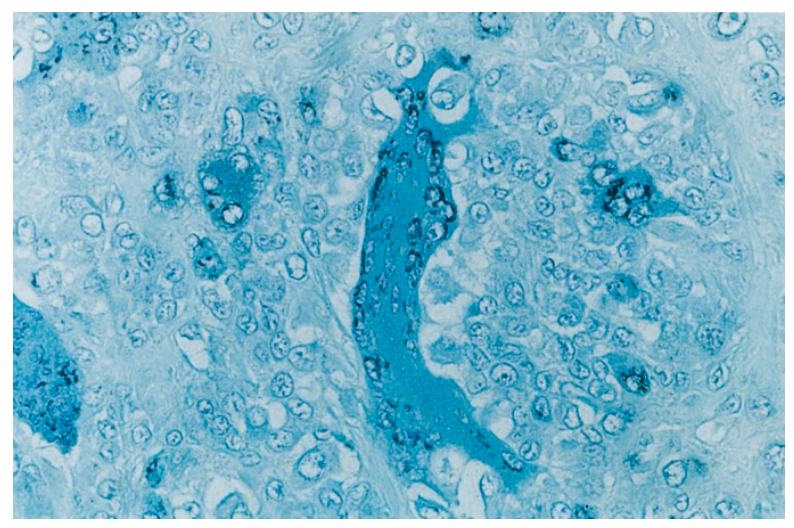

FIGURE 4. Cystatin C-positive giant cells (black) in close apposition to two mononuclear cells. Counterstaining with light green and hematoxylin $(600 \times)$.

\section{DISCUSSION}

GCTTS is a proliferative synovial disorder that is divided into localized and diffuse form. The localized type, also called nodular tenosynovitis, typically occurs on the digits, where it represents the

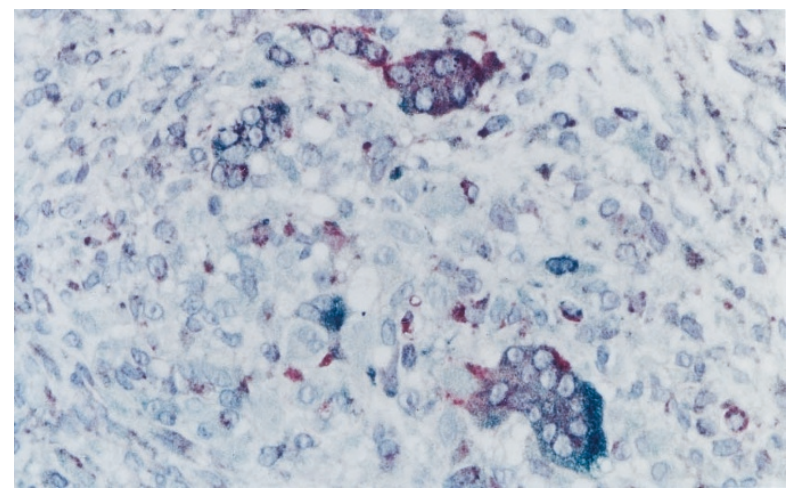

FIGURE 5. Colocalization of CD68 (red) and cystatin C (black) in giant cells. Only the minority of mononuclear cells is positive for both molecules. Counterstaining with hematoxylin $(500 \times)$.

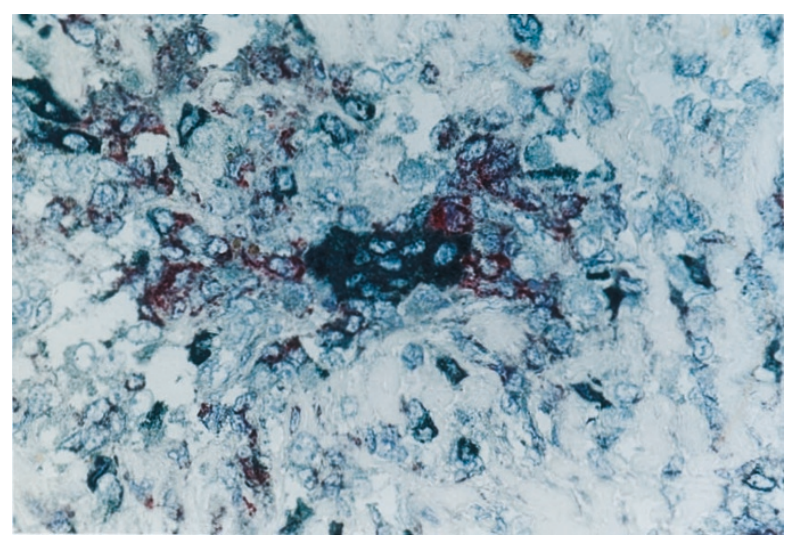

FIGURE 6. Double labeling of cathepsin B (red) and cystatin C (black). Weak coexpression of both proteins in a few mononuclear cells (MC). Note that giant cells expressing cystatin $\mathrm{C}$ are surrounded with numerous cathepsin B-positive MC. Counterstaining with hematoxylin $(600 \times)$.

second most common tumor after ganglion (1). Although GCTTS usually causes no particular symptoms other than a painless, palpable nodule, it induces osseous erosion $(1,6)$. The radiographic findings of Karasick and Karasick (6) demonstrated bone erosion in up to $10-20 \%$. This bone erosion is suggested to occur because of pressure from the soft-tissue mass (6). However, invasion and destruction of the adjacent bone matrix has been observed as well $(8,11)$. Furthermore, GC derived from GCTTS have been shown to resorb bone (12). Bone resorption and destruction requires the proteinolytic activity of matrix-degrading enzymes such as metalloproteinases and cysteine proteinases $(15,17,20)$. To analyze whether matrixdegrading proteases might participate in bone erosion in GCTTS, we investigated the expression of the cysteine proteinases cathepsins B and $\mathrm{K}$.

Most interestingly, the GC strongly expressed cathepsin $\mathrm{K}$ and cystatin $\mathrm{C}$, whereas cathepsin B was detected at very low levels. Expression of cathepsin $\mathrm{K}$ has been demonstrated in different cell populations like synovial fibroblasts (30), macrophages 
and smooth muscle cells in atheroma (31), and breast cancer cells (32). However, several studies indicate that cathepsin $\mathrm{K}$ is predominantly expressed in osteoclasts $(27,33,34)$. GC sharing phenotypic features of osteoclasts are found within several diseased synovial tissues, as in osteoarthritis (OA), rheumatoid arthritis, pigmented villonodular synovitis, and GCTTS. These previous studies examined the expression of common osteoclastic markers like tartrate-resistant acid phosphatase (TRAP), the vitronectin receptor (CD51), CD68, and the calcitonin receptor (main results are summarized in Table 2.). Recently, cathepsin K mRNA expression was found in TRAP-positive synovial GC in $\mathrm{OA}$, whereas these cells lacked expression of cathepsin B mRNA (39). In rheumatoid arthritis, cathepsin K mRNA was detected in synovial GC as well (30). Furthermore, rheumatoid GC revealed strong expression of cystatin $\mathrm{C}$ protein but not of cathepsin B (37). Osteoclasts have been shown to abundantly express cystatin $\mathrm{C}$ and cathepsin $\mathrm{K}$, whereas cathepsin B was detected at very low levels $(29,33)$, similar to the case of the data in the present study. Taken together, our analysis supports the view that GC in GCTTS and osteoclasts exhibit a very similar phenotype and might thus be closely associated.

Athanasou et al. concluded from their studies that GC derived from GCTTS are capable of bone resorption (12). Cathepsin $\mathrm{K}$ is considered to play a key role in the resorption of bone matrix, as it degrades large amounts of the major bone collagen Type I as well as the bone matrix protein osteonectin $(20,21)$. Furthermore, it has been described to be unique among mammalian proteinases because it is able to cleave the collagen molecule both inside and outside of the collagen helix (21). The present study revealed strong expression of cathepsin $\mathrm{K}$ in GC of GCTTS. In other synovial lesions like rheumatoid arthritis and OA, this cysteine proteinase is thought to be involved in bone degradation $(30,39)$. If bone erosion in GCTTS is mediated by matrixdegrading enzymes, we suggest that cathepsin $\mathrm{K}$ is critical for this process as well.

In contrast to cathepsin $\mathrm{K}$, cathepsin B staining was strongly positive in the $\mathrm{MC}$, indicating that these cells express large amounts of this enzyme. Cathepsin B-positive cells often coexpressed HAM56 too, which is a known marker for mononuclear macrophages in GCTTS $(2,40)$. Cathepsin B may be involved in cartilage and bone destruction by degrading proteoglycans, different collagen types (II, IX, and XI), and the bone matrix protein osteocalcin as well as by activating the collagenolytic metalloproteinases interstitial collagenase (MMP-1) and stromelysin (MMP-3; 17-19). The expression of both MMP-1 and MMP-3 has been examined in pigmented villonodular synovitis, which is considered to be a closely related entity of GCTTS. Interestingly, MMP-1 and MMP-3 were predominantly detectable in MC of the synovial membrane, whereas GC were not noted to express these proteinases in significant amounts (13). It is thus possible that cathepsin B participates in bone erosion in pigmented villonodular synovitis and GCTTS by either matrix degradation or activation of MMP as well.

Destruction of the extracellular matrix is the result of a shifted balance between the matrix degrading enzyme and its inhibitor in favor of the enzyme $(14,15)$. Therefore, we included the investigation of the relationship of cathepsin B and its major inhibitor cystatin C (26) in this study. Strong expression of cystatin $\mathrm{C}$ was found in most of the cathepsin B-negative and CD68-positive GC, but only in the minority of the cathepsin B-positive MC. The finding that in GCTTS, cathepsin B and cystatin C are slightly coexpressed favors the view that cathepsin $B$ is only weakly inhibited by its major endogenous inhibitor and might therefore be involved in matrix degradation.

Although it is still a matter of debate whether GCTTS is of histiocytic or synovial cell origin, it is generally considered that the GC in GCTTS form by the fusion of macrophage-like $\mathrm{MC}(2,7,10)$. In the present study, several MC were observed that were in close apposition with GC. These MC often expressed cathepsin $\mathrm{B}$ as well as the macrophage marker HAM56. In some cases, GC were found to express cathepsin B in distinct cellular compartments. This could be interpreted as resulting from the fusion with cathepsin B-positive MC. On the

TABLE 2. Expression of Common Osteoclastic Markers, Cysteine Proteinases Cathepsins B and K and Cystatin C in GC in Synovial Lesions

\begin{tabular}{|c|c|c|c|c|c|c|c|}
\hline & TRAP & CD51 & CD68 & CTR & CB & CK & $\mathrm{CC}$ \\
\hline RA & $+(35)$ & $+(35)$ & $+(35)$ & $+(36)$ & $-(37)$ & $+(30)$ & $+(37)$ \\
\hline $\mathrm{OA}$ & $+(38)$ & $+(38)$ & $+(35)$ & ND & $-(39)$ & $+(39)$ & ND \\
\hline PVNS & $+(9)$ & $+(9)$ & $+(2)$ & $+(9)$ & ND & ND & ND \\
\hline GCTTS & $+(9)$ & $+(9)$ & $+^{a}$ & $+(9)$ & $-a$ & $+^{a}$ & $+^{a}$ \\
\hline
\end{tabular}

ND, study not done; +, strong expression; -, expressed at low levels or no expression; CB, cathepsin B; CC, cystatin C; CK, cathepsin K; CTR, calcitonin receptor; GCTTS, giant cell tumor of tendon sheath; OA, osteoarthritis; PVNS, pigmented villonodular synovitis; RA, rheumatoid arthritis; TRAP, tartrate-resistant acid phosphatase. Numbers in parentheses indicate reference citation numbers.

${ }^{a}$ Shows results of the present study. 
other hand, GC surrounded with cathepsin B-positive MC frequently revealed a strong immunoreactivity for cystatin C. (Interestingly, immunostaining of cathepsin $\mathrm{K}$ revealed a result similar to that of cystatin $\mathrm{C}$, as both could be detected mainly in the GC. However, it has not yet been investigated whether cystatin $\mathrm{C}$ is able to bind and inhibit cathepsin K.) It has been suggested that cystatin $\mathrm{C}$ functions extracellularly (41). The results of Pierre and Mellman (42) indicated that cystatin C can inhibit cathepsin activity intracellularly as well. Thus, it remains to be elucidated whether cystatin C, strongly expressed in GC, performs cytoprotective functions during fusion with cathepsin B-rich MC.

In summary, these data demonstrate for the first time that the cysteine proteinases cathepsins B and $\mathrm{K}$, as well as the endogenous inhibitor of the cysteine proteinases, cystatin $\mathrm{C}$, are expressed in GCTTS. Because we have shown that GC exhibit a similar staining pattern as osteoclasts in previous studies, in other words, positivity for CD68, cathep$\sin \mathrm{K}$, and cystatin $\mathrm{C}$ but only faint expression of cathepsin B, both cell populations might be closely associated. Furthermore, if bone erosion in GCTTS is mediated by matrix-degrading enzymes, we suggest that because of strong expression of cathepsin $\mathrm{B}$ and $\mathrm{K}$, both cysteine proteinases are involved in this process.

Acknowledgments: We thank Luise Meyer and Sandra Gerecht, Institute for Pathology, University of Mainz, Germany, for their technical assistance.

\section{REFERENCES}

1. Enzinger FM, Weiss SW. Benign tumors and tumorlike lesions of synovial tissue. In: Enzinger FM, Weiss SW, editors. Soft tissue tumors. 3rd ed. St. Louis: Mosby; 1995. pp. 73556.

2. O'Connell JX, Fanburg JC, Rosenberg AE. Giant cell tumor of tendon sheath and pigmented villonodular synovitis: immunophenotype suggests a synovial cell origin. Hum Pathol 1995;26:771-5.

3. Vogrincic GS, O'Connell JX, Gilks CB. Giant cell tumor of tendon sheath is a polyclonal cellular proliferation. Hum Pathol 1997;28:815-9.

4. Dal Cin P, Sciot R, Samson I, de Smet L, de Wever I, van Damme B, et al. Cytogenetic characterization of tenosynovial giant cell tumors (nodular tenosynovitis). Cancer Res 1994;54:3986-7.

5. Sciot R, Rosai J, Dal Cin P, de Wever I, Fletcher C, Mandahl $\mathrm{N}$, et al. Analysis of 35 cases of localized and diffuse tenosynovial giant cell tumor: a report from the chromosomes and morphology (CHAMP) study group. Mod Pathol 1999;12: 576-9.

6. Karasick D, Karasick S. Giant cell tumor of tendon sheath: spectrum of radiologic findings. Skeletal Radiol 1992;21:21924.

7. Alguacil-Garcia A, Unni KK, Goellner JR. Giant cell tumor of tendon sheath and pigmented villonodular synovitis. An ultrastructural study. Am J Clin Pathol 1978;69:6-17.
8. Wood GS, Beckstead JH, Medeiros LJ, Kempson RL, Warnke RA. The cells of giant cell tumor of tendon sheath resemble osteoclasts. Am J Surg Pathol 1988;12:444-52.

9. Darling JM, Goldring SR, Harada Y, Handel ML, Glowacki J, Gravallese EM. Multinucleated cells in pigmented villonodular synovitis and giant cell tumor of tendon sheath express features of osteoclasts. Am J Pathol 1997;150:1383-93.

10. Chambers TJ. Multinucleate giant cells. J Pathol 1978;126: $125-48$

11. Carstens PHB, Howell RS. Malignant giant cell tumor of tendon sheath. Virchows Arch A Pathol Anat 1979;382:23743.

12. Athanasou NA, Quinn J, Ferguson DJP, McGee JOD. Bone resorption by macrophage polykaryons of giant cell tumor of tendon sheath. Br J Cancer 1991;63:527-33.

13. Darling JM, Glimcher LH, Shortkroff S, Albano B, Gravallese E. Expression of metalloproteinases in pigmented villonodular synovitis. Hum Pathol 1994;25:825-30.

14. Keyszer G, Redlich A, Häupl T, Zacher J, Sparmann M, Ungethüm U, et al. Differential expression of cathepsins B and L compared with matrix metalloproteinases and their respective inhibitors in rheumatoid arthritis and osteoarthritis: a parallel investigation by semiquantitative reverse transcriptase-polymerase chain reaction and immunohistochemistry. Arthritis Rheum 1998;41:1378-87.

15. McCachren SS. Expression of metalloproteinases and metalloproteinases inhibitor in human arthritic synovium. Arthritis Rheum 1991;34:1085-93.

16. Maciewicz RA, Wotton SF. Degradation of cartilage matrix components by the cysteine proteinases, cathepsins B and L. Biomed Biochim Acta 1991;50:561-4.

17. Baumgrass R, Williamson MK, Price PA. Identification of peptide fragments generated by digestion of bovine and human osteocalcin with the lysosomal proteinases cathepsin B, D, L, H and S. J Bone Miner Res 1997;12:447-55.

18. Eeckhout Y, Vaes G. Further studies on the activation of procollagenase, the latent precursor of bone collagenase: effects of lysosomal cathepsin B, plasmin and kallikrein, and spontaneous activation. Biochem J 1977;166:21-31.

19. Murphy G, Ward R, Gavrilovic J, Atkinson S. Physiological mechanisms for metalloproteinase activation. Matrix 1992;(1 Suppl):224-30.

20. Bossard MJ, Tomaszek TA, Thompson SK, Amegadzie BY, Hannings CR, Jones J, et al. Proteolytic activity of human osteoclast cathepsin K. Expression, purification, activation, and substrate identification. J Biol Chem 1996;271:12517-24.

21. Garnero P, Borel O, Byrjalsen I, Ferreras M, Drake FH, McQueney MS, et al. The collagenolytic activity of cathepsin K is unique among mammalian proteinases. J Biol Chem 1998; 273:32347-52.

22. Hou WS, Bromme D, Zhao Y, Mehler E, Dushey C, Weinstein $\mathrm{H}$, et al. Characterization of novel cathepsin $\mathrm{K}$ mutations in the pro and mature polypeptide region causing pycnodysostosis. J Clin Invest 1999;103:731-8.

23. Van Noorden CJ, Smith RE, Rasnick D. Cysteine proteinase activity in arthritic rat knee joints and the effects of a selective systemic inhibitor, Z-Phe-AlaCH2F. J Rheumatol 1988; 15:1525-35.

24. Esser RE, Watts LM, Angelo RA, Thornburg LP, Prior JJ, Palmer JT. The effects of fluoromethyl ketone inhibitors of cathepsin B on adjuvant induced arthritis. J Rheumatol 1993; 20:1176-83.

25. Katunuma N, Matsui A, Inubushi T, Murata E, Kakegawa H, Ohba Y, et al. Structure-based development of pyridoxal propionate derivatives as specific inhibitors of cathepsin $\mathrm{K}$ in vitro and in vivo. Biochem Biophys Res Commun 2000; 267:850-4. 
26. Hall A, Hakansson K, Mason RW, Grubb A, Abrahamson M. Structural basis for the biological specifity of cystatin C. J Biol Chem 1995;270:5115-21.

27. Littlewood-Evans AJ, Kokubo T, Ishibashi O, Inaoka T, Wlodarski B, Gallagher JA, et al. Localization of cathepsin $\mathrm{K}$ in human osteoclasts by in situ hybridization and immunohistochemistry. Bone 1997;20:81-6.

28. Cordell JL, Falini B, Erber WN, Ghosh AK, Abdulaziz Z, Macdonald S, et al. Immunoenzymatic labeling of monoclonal antibodies using immune complexes of alkaline phosphatase and monoclonal anti-alkaline phosphatase (APAAP complexes). J Histochem Cytochem 1984;32:219-29.

29. Hansen T, Petrow PK, Gaumann A, Keyszer GM, Eysel P, Eckardt A, et al. Cathepsin B and its endogenous inhibitor cystatin $\mathrm{C}$ in rheumatoid arthritis synovium. J Rheumatol 2000;27:859-65.

30. Hummel KM, Petrow PK, Franz JK, Müller-Ladner U, Aicher WK, Gay R, et al. Cysteine proteinase cathepsin K mRNA is expressed in synovium of patients with rheumatoid athritis and is detected at sites of synovial bone destruction. J Rheumatol 1998;25:1887-94.

31. Sukhova GK, Shi GP, Simon DI, Chapman HA, Libby P. Expression of the elastolytic cathepsins $\mathrm{S}$ and $\mathrm{K}$ in human atheroma and regulation of their production in smooth muscle cells. J Clin Invest 1998;102:576-83.

32. Littlewood-Evans AJ, Bilbe G, Bowler WB, Farley D, Wlodarski B, Kokubo T, et al. The osteoclast-associated proteinase cathepsin $\mathrm{K}$ is expressed in human breast carcinoma. Cancer Res 1997;57:5386-90.

33. Drake FH, Dodds RA, James IE, Connor J, Debouck C, Richardson S, et al. Cathepsin $\mathrm{K}$, but not cathepsins $\mathrm{B}, \mathrm{L}$, or $\mathrm{S}$, is abundantly expressed in human osteoclasts. J Biol Chem 1996;271:12511-6.
34. Yamaza T, Goto T, Kamiya T, Kobayashi Y, Sakai H, Tanaka T. Study of immunoelectron microscopic localization of cathepsin $\mathrm{K}$ in osteoclasts and other bone cells in the mouse femur. Bone 1998;23:499-509.

35. Wilkinson LS, Pitsillides AA, Edwards JCW. Giant cells in arthritic synovium. Ann Rheum Dis 1993;52:182-4.

36. Gravallese EM, Harada Y, Wang JT, Gorn AH, Thornhill TS, Goldring SR. Identification of cell types responsible for bone resorption in rheumatoid arthritis and juvenile rheumatoid arthritis. Am J Pathol 1998;152:943-51.

37. Hansen T, Petrow PK, Gaumann A, Keyszer G, Bräuer R, Kriegsmann J. Synovial giant cells in rheumatoid arthritis: expression of cystatin C, but not of cathepsin B. Exp Toxic Pathol 2000;52:312-6.

38. Connor JR, Dodds RA, James IE, Gowen M. Human osteoclast and giant cell differentiation: the apparent switch from nonspecific esterase to tartrate resistant acid phosphatase activity coincides with the in situ expression of osteopontin mRNA. J Histochem Cytochem 1995;43:1193-201.

39. Dodds RA, Connor JR, Drake FH, Gowen M. Expression of cathepsin $\mathrm{K}$ messenger RNA in giant cells and their precursors in human osteoarthritic synovial tissues. Arthritis Rheum 1999;42:1588-93.

40. Maluf HM, De Young BR, Swanson PE, Wick MR. Fibroma and giant cell tumor of tendon sheath: a comparative histological and immunohistological study. Mod Pathol 1995;8:155-9.

41. Abrahamson M, Grubb A, Olafsson I, Lundwall Å. Molecular cloning and sequence anlysis of cDNA coding for the precursor of the human cysteine proteinase inhibitor cystatin C. FEBS Lett 1987;216:229-33.

42. Pierre P, Mellman I. Developmental regulation of invariant chain proteolysis controls MHC class II trafficking in mouse dendritic cells. Cell 1998;93:1135-45. 